\title{
DIAGNÓSTICO DE FALHA DE TRANSFERÊNCIA DE IMUNIDADE PASSIVA EM BEZERROS ATRAVÉS DA DETERMINAÇÃO DE PROTEÍNA TOTAL E DE SUAS FRAÇÕES ELETROFORÉTICAS, IMUNOGLOBULINAS G E M E DA ATIVIDADE DA GAMA GLUTAMIL TRANSFERASE NO SORO SANGÜÍNEO
}

\author{
DIAGNOSIS OF PASSIVE IMMUNITY TRANSFER FAILURE IN CALVES BY TOTAL PROTEIN \\ AND ITS ELETROPHORETIC FRACTIONS, IMMUNOGLOBULINS G AND M QUANTIFICATION \\ AND GAMMA GLUTAMYL TRANSFERASE ACTIVITY IN SERUM
}

\author{
Francisco Leydson Formiga Feitosa ${ }^{1}$ Eduardo Harry Birgel ${ }^{2}$ Regina Mieko Sakata Mirandola $^{3}$ \\ Sílvia Helena Venturoli Perri ${ }^{4}$
}

RESUMO

Determinou-se a concentração de proteína total e de suas frações (albumina, alfa globulina, beta globulina e gama globulina), imunoglobulinas $G$ e $M$, bem como, a atividade da gama glutamil transferase (GGT) em amostras sangüíneas de 40 bezerros com 24 horas de vida, com o objetivo de identificar a ocorrência de falha de transferência de imunidade passiva em bezerros. A maioria dos animais que morreu nos primeiros meses de vida apresentou, às 24 horas de vida, menores teores de proteína total, das frações beta e gama globulina, de IgG e IgM e de GGT do que os animais que sobreviveram.

Palavras-chave : imunidade passiva, bovino, imunoglobulinas.

\section{SUMMARY}

The total protein and its fractions (albumin, alpha globulin, beta globulin and gamma globulin), $G$ and $M$ immunoglobulins and the activity of gamma glutamyl transferase were determined in the blood samples of 40 calves, 24 hours old, in an attempt to identify calves with failure of passive immunoglobulin transfer. The majority of newborn calves that died in the first months of life had lower levels of total protein, beta globulin, gamma globulin, IgG, IgM and GGT, than those found in newborn calves that survived.

Key words : passive immunity, bovine, immunoglobulins.

\section{INTRODUÇÃO}

Vários exames laboratoriais têm sido desenvolvidos e testados para determinar direta e/ou indiretamente os níveis de imunoglobulinas em animais recém-nascidos. A constatação de que os neonatos que possuíam uma baixa imunidade passiva apresentavam maiores índices de mortalidade e um menor desempenho produtivo fez com que houvesse um grande estímulo no desenvolvimento de pesquisas relacionadas ao tema.

Nos bovinos, estão identificadas e caracterizadas quatro frações de imunoglobulinas : $\operatorname{IgG}$, IgM, IgA e IgE (BUTLER, 1983 ; COLLARD et al. 1984). As imunoglobulinas, quando separadas eletroforeticamente, encontram-se distribuídas, principalmente, nas frações beta e gama globulinas do soro sangüíneo normal (BUTLER, 1969).

PFEIFFER et al. (1977), estudando os níveis de imunoglobulinas séricas através dos métodos de imunodifusão radial, turbidimetria pelo sulfato de zinco, refratometria e eletroforese, constataram erros mais significativos nos resultados obtidos através da imunodifusão radial, principalmente nas amostras

\footnotetext{
${ }^{1}$ Médico Veterinário, Professor assistente, Doutor do Curso de Medicina Veterinária da FOA, Universidade Estadual Paulista (UNESP). Araçatuba - São-Paulo. E-mail: leydsonf@fmva.unesp.br. Autor para correspondência.

${ }^{2}$ Médico Veterinário, Professor da Faculdade de Medicina Veterinária e Zootecnia, Universidade de São Paulo (USP). São Paulo, Capital.

${ }^{3}$ Biólogo, Laboratório de Pesquisa da Faculdade de Medicina Veterinária e Zootecnia, USP, São Paulo, SP.

${ }^{4}$ Matemático, Professor Assistente, Doutor do Curso de Medicina Veterinária da FOA, UNESP, Araçatuba, SP Recebido para publicação em 22.09.99. Aprovado em 19.07.00
} 
que apresentavam grandes concentrações de imunoglobulinas $(3,0$ a $5,0 \mathrm{~g} / \mathrm{d} \ell)$. Em tais amostras, os resultados obtidos variavam, apresentando diferenças relativas entre 41,1 a $180 \%$, quando comparados esses valores com os reais, obtidos após diluições corretoras. RUBIO et al. (1991) encontraram resultados mais precisos quando da realização da turbidimetria pelo sulfato de zinco em amostras previamente diluídas (1:3). HUDGENS et al. (1996) propuseram a utilização de soluções com maiores concentrações de sulfato de zinco, com o objetivo de melhorar a especificidade do teste.

THOMPSON \& PAULI (1981) reportaram que a grande atividade de gama glutamil transferase (GGT) no soro sangüíneo de bezerros recém-nascidos é conseqüente à absorção integral das moléculas da enzima presentes no colostro. FAGLIARI $\boldsymbol{e t}$ al. (1996) verificaram a existência de correlação positiva entre os valores de gama globulina e a atividade da GGT, com variações acentuadas entre os valores no momento do nascimento e aqueles verificados 24 a 30 horas após o nascimento .

Este trabalho teve como objetivo avaliar a eficácia da determinação da concentração de proteína total e de suas frações eletroforéticas, imunoglobulinas $\mathrm{G}$ e $\mathrm{M}$ e da atividade da gama glutamil transferase, na detecção de falha de transferência de imunidade passiva em bezerros da raça Holandesa com um dia de vida.

\section{MATERIAL E MÉTODOS}

Foram utilizados 40 animais da raça holandesa, sem distinção de sexos, os quais permaneceram com as mães por um período de até 24 horas (16 a 24 horas), ingerindo colostro "ad libitum". Os mesmos foram submetidos a avaliações clínicas periódicas desde o nascimento até os dois meses de idade. As colheitas de sangue para a obtenção de soro foram realizadas às 24 horas de vida, por punção da veia jugular.

A proteína sérica total foi determinada pelo método do biureto segundo GORNALL et $\boldsymbol{a l}$. (1949), modificado por STRUFALDI (1987), usando-se para tal um analisador bioquímico automático ${ }^{1}$ em comprimento de onda de 550nm. A migração eletroforética para separação das frações protéicas do soro sangüíneo foi efetuada segundo as técnicas descritas por FRIEDMAN (1961). A leitura e o cálculo do fracionamento eletroforético foram realizados em densitômetro ${ }^{2}$, com separação manual das várias frações protéicas (albumina, alfa, beta e gama globulinas).
As determinações das imunoglobulinas séricas através da imunodifusão radial foram feitas segundo a técnica de MANCINI et al. (1965), utilizando-se placas de ágar ${ }^{3}$ incorporadas com antisoros específicos para as classes de imunoglobulinas $\mathrm{G}$ e $\mathrm{M}$ de bovinos. A avaliação indireta dos teores séricos de imunoglobulina $\mathrm{G}$, através de turbidimetria pelo sulfato de zinco, foi realizada segundo PFEIFFER et al. (1977). A atividade sérica da gama glutamil-transferase (GGT) foi determinada pelo método cinético colorimétrico, recomendado pela International Federation of Clinical Chemistry (IFCC) utilizando-se kit comercial ${ }^{4}$, segundo técnica modificada de SZASZ et al. (1969), em analisador bioquímico automático ${ }^{1}$, no comprimento de onda de $405 \mathrm{~nm}$.

Para a determinação dos valores de referência dos constituintes no soro sangüíneo de bezerros com 24 horas de vida foi realizada estatística descritiva pela determinação dos valores de tendência central (média e mediana) e dos valores de dispersão (desvio padrão, coeficiente de variação e valores mínimo e máximo) para cada variável, avaliando-se , ainda, as correlações entre as variáveis estudadas. Para a verificação da existência de diferenças entre o grupo de bezerros que morreu e o grupo que sobreviveu, realizou-se análise de variância para cada grupo, às 24 horas de vida. Todos os testes foram aplicados em nível de significância de 5\% (ZAR, 1984).

\section{RESULTADOS E DISCUSSÃO}

Dos 40 animais utilizados na presente pesquisa, nove $(22,5 \%)$ morreram antes de completarem 60 dias de vida, acometidos, principalmente, por diarréia infecciosa e/ou broncopneumonia. No entanto, entre esses nove bezerros, um morreu acidentalmente, por enforcamento nas correntes de contenção, e outro, em consequiência de um possível trauma abdominal, determinante de hemorragia interna. Os outros sete animais que morreram no transcurso do experimento apresentavam menores concentrações médias de proteína total, das frações gama e beta globulinas, das imunoglobulinas $\mathrm{G}$ e $\mathrm{M}$ e da atividade da gama glutamil transferase (Tabela 1).

Existe uma enorme discordância de opiniões entre os vários autores quanto à definição de um valor ideal de proteína total, da concentração de imunoglobulinas e da atividade da GGT no soro sangüíneo de bezerros recém-nascidos, que lhes confira uma adequada imunidade passiva. Por exemplo, a avaliação dos resultados individuais, para a concentração de proteína total no soro san- 
Tabela 1 - Valores médios e respectivos desvios-padrões $(\bar{X} \pm s)$ das concentrações de proteína total (PT), albumina (ALB), alfa globulina (ALFA), beta globulina (BETA), gama globulina (GAMA), imunoglobulina G / turbidimetria (IgGTurb.), imunoglobulinas G e M / imunodifusão radial (IgG-IR e IgM-IR) e gama glutamil transferase (GGT), do soro sangüíneo de bezerros da raça holandesa com 24 horas de vida, dos grupos experimentais formados por animais que sobreviveram ou morreram de enfermidades infecciosas durante o período experimental. Araçatuba - SP, 1998.

\begin{tabular}{|c|c|c|c|c|c|c|c|c|c|c|}
\hline VARIÁVEIS & \multicolumn{3}{|c|}{$\begin{array}{c}\text { ÓBITO } \\
\left(\mathrm{n}^{\circ} 7 * * / 18,4 \%\right) \\
\overline{\mathrm{X}} \pm \mathrm{s}\end{array}$} & \multicolumn{3}{|c|}{$\begin{array}{c}\text { SOBREVIVENTE } \\
\left(\mathrm{n}^{\circ} 31 / 81,6 \%\right) \\
\overline{\mathrm{X}} \pm \mathrm{s}\end{array}$} & \multicolumn{4}{|c|}{$\begin{array}{c}\text { TOTAL } \\
\begin{array}{l}\left(\mathrm{n}^{\circ} 40 / 100 \%\right) \\
\overline{\mathrm{X}} \pm \mathrm{s}\end{array}\end{array}$} \\
\hline PT (g/dl) & 4,71 & \pm & 0,84 & 7,02 & \pm & 0,96 & 6,55 & \pm & 1,31 & $*$ \\
\hline $\operatorname{ALB}(\mathrm{g} / \mathrm{dl})$ & 2,52 & \pm & 0,35 & 2,64 & \pm & 3,35 & 2,61 & \pm & 0,35 & \\
\hline $\operatorname{ALFA}(\mathrm{g} / \mathrm{dl})$ & 0,97 & \pm & 0,20 & 0,94 & \pm & 0,28 & 0,95 & \pm & 0,26 & \\
\hline BETA (g/dl) & 0,57 & \pm & 0,19 & 0,93 & \pm & 0,28 & 0,86 & \pm & 0,30 & $*$ \\
\hline GAMA (g/dl) & 0,65 & \pm & 0,50 & 2,51 & \pm & 0,82 & 2,14 & \pm & 1,07 & $*$ \\
\hline IgG-Turb. (g/dl) & 1,04 & \pm & 0,79 & 2,97 & \pm & 0,66 & 3,10 & \pm & 1,50 & $*$ \\
\hline IgG-IR (g/dl) & 1,01 & \pm & 0,70 & 3,82 & \pm & 0,95 & 2,60 & \pm & 1,34 & $*$ \\
\hline $\operatorname{IgM-IR~(g/dl)~}$ & 0,09 & \pm & 0,06 & 0,28 & \pm & 0,12 & 0,22 & \pm & 0,13 & $*$ \\
\hline GGT (UI/1) & 105,13 & \pm & 31,37 & 840,55 & \pm & 480,72 & 702,45 & \pm & 24,93 & $*$ \\
\hline
\end{tabular}

*Demonstraram-se diferenças estatisticamente significativas $(\mathrm{p}<0,05)$ entre os dois grupos.

** Os dois animais que morreram por enforcamento e trauma abdominal não foram incluídos nesse grupo.

güíneo às 24 horas, demonstrou que 14 dos 40 animais $(35 \%)$ possuiriam uma falha de imunidade passiva, se fosse adotada a classificação de NAYLOR $\boldsymbol{e t}$ al. (1977), que observaram a ocorrência de óbitos em bezerros que tinham concentração de proteína sérica total, menor ou igual a $6 \mathrm{~g} / \mathrm{d} \ell$. Nove dos animais utilizados nesta tese $(22,5 \%)$ apresentariam o mesmo problema, caso fosse considerado o conceito de estratificação apresentado por HEATH (1992), que postulou um valor sérico mínimo de $5,5 \mathrm{~g} / \mathrm{d} \ell$ de proteína total, para que houvesse uma proteção satisfatória dos animais recémnascidos contra agentes agressores. Mas, apenas quatro dos quarenta animais avaliados $(10 \%)$ seriam hipogamaglobulinêmicos, se fossem seguidos os critérios sugeridos por REA et al. (1996), para os quais haveria falha de transferência de imunidade passiva nos bezerros com valores mínimos de proteína total de 5,0 , 4,8 e 4,5g/d $\ell$. Os resultados apresentados demonstraram uma taxa de mortalidade de $100 \%$ nos bezerros que apresentavam níveis séricos de proteína total compreendidos entre 3,4 e 4,5g/d $\ell$, enquanto o teor sérico de proteína total dos 23 animais que sobreviveram $(57,5 \%)$ foram iguais ou maiores que $6,6 \mathrm{~g} / \mathrm{d} \ell$, às 24 horas de vida. Sete, dos 40 bezerros estudados, possuíam concentração sérica média da fração gama globulina menor do que $1,0 \mathrm{~g} / \mathrm{d} \ell$, dos quais se constataram seis $(85,7 \%)$ casos de óbito. Por outro lado, as frações albumina e alfa globulina não apresentaram diferenças estatisticamente significativas entre os resultados do grupo de animais que sobreviveu ou morreu durante a fase experimental, indicando que as diferenças nos valores totais estão associados a variações nas frações beta e gama globulinas.

Com relação às concentrações séricas de $\mathrm{IgG}$, denotou-se que as mesmas foram menores do que $0,5 \mathrm{~g} / \mathrm{d} \ell$ após a ingestão de colostro em três animais que morreram $(7,5 \%)$ no transcurso da fase experimental, comprovando relatos semelhantes feitos por SELIM et al. (1995). Entretanto, um dos sete animais que morreram apresentava níveis séricos de $\operatorname{IgG}$ iguais a $0,68 \mathrm{~g} / \mathrm{d} \ell$, valor situado acima do limiar estabelecido por ODDE (1988), mas localizado dentro da faixa de maior risco descrita por MICUNOVICK et al. (1996), que variou entre 0,63 e $1,26 \mathrm{~g} / \mathrm{d} \ell$, em bezerros apresentando problemas gastrintestinais e respiratórios.

A determinação da atividade da GGT permitiu observar que oito dos 40 animais (20\%) avaliados apresentavam uma atividade da GGT menor do que 200UI/ $\ell$, valor esse utilizado por PERINO et al. (1993) para diagnosticar a ocorrência de falha na transferência de imunidade passiva sendo que, destes, sete morreram $(87,5 \%)$.

Todos os testes avaliados apresentaram vantagens e desvantagens quando de sua utilização. Inúmeros pesquisadores têm usado o valor da proteína sérica total como um método indireto para estimar a concentração de imunoglobulinas no soro de bezerros. O método é baseado no simples fato de que valores baixos de proteína total refletem uma falha na transferência de anticorpos maternos. Como no recém-nascido o nível de albumina é pouco variável, as diferenças nas concentrações protéicas devem-se, quase que exclusivamente, à absorção de imunoglobulinas após a ingestão de colostro. Ressalta-se, porém, a dificuldade de se avaliar a ocorrência de falha de transferência de imunidade passiva em animais neonatos que se encontrem desidratados. A técnica de eletroforese, apesar de não detectar classes específicas de imunoglobulinas e ser de execução complexa e mais demorada, possui tecnologia nacional e custo operacional relativamente pequeno. Outro ponto positivo a favor do uso rotineiro da determinação eletroforética da fração gama globulina foi o de apresentar resultados consistentes num tempo máximo de duas horas após o início do seu processamento, permitindo, ao clínico, maiores chances de intervenção nos casos de deficiente transferência de imunidade passiva aos bezerros recémnascidos . 
Apesar da simplicidade na execução da técnica de imunodifusão radial, constatou-se a ocorrência de inúmeros erros, observados, particularmente, em amostras que possuíam grandes concentrações de imunoglobulina $\mathrm{G}(3,5$ a $5,0 \mathrm{~g} / \mathrm{d} \ell)$, como reportou PFEIFFER $\boldsymbol{e t}$ al. (1977). Em uma dessas amostras, por exemplo, verificou-se uma concentração de 7,5g/d $\ell$ de $\mathrm{IgG}$, valor esse incompatível com o da proteína total do respectivo soro que era de aproximadamente $8,0 \mathrm{~g} / \mathrm{d} \ell$. Após a realização de inúmeras repetições, não se demonstrando uma possível falha de execução da técnica, concluiu-se que, para resolução do problema, era necessário o uso de diluições apropriadas para o adequado exame de tais amostras.

Uma das desvantagens da imunodifusão radial é, sem dúvida, o seu alto custo, pois como as placas de gel-ágar sensibilizadas com anticorpos contra imunoglobulinas de bovinos não são produzidas no Brasil, o processamento das amostras só é possível mediante a importação desse material, fazendo ser o seu uso, na rotina, impraticável e economicamente inviável. O tempo gasto para realização da imunodifusão radial e apresentação dos resultados é outro fator limitante para seu uso rotineiro no diagnóstico e/ou para a detecção precoce de falha na transferência de imunidade passiva em bezerros, pois as leituras das placas de IgG e IgM, por exemplo, só podiam ser feitas, às 72 e às 96 horas, respectivamente, após a aplicação das amostras de soro nas placas, o que poderia impedir uma assistência clínica imediata aos animais com hipogamaglobulinemia.

A prova da turbidimetria pelo sulfato de zinco mostrou ser de fácil execução e de baixíssimo custo, podendo ser utilizada como método de escolha para se detectar, precocemente, os animais com falhas de transferência de imunidade materna, pois seus resultados puderam ser conhecidos em cerca de uma hora. Apesar das diferenças de sensibilidade existentes entre as duas provas, os valores de imunoglobulinas do soro sangüíneo de bezerros determinados por turbidimetria foram, praticamente, iguais aos de $\operatorname{IgG}$ quantificados pela imunodifusão radial.

Da mesma forma que o teste da imunodifusão radial, a prova turbidimétrica pelo sulfato de zinco apresentou, nas amostras contendo maiores concentrações de imunoglobulinas, valores considerados anômalos, mesmo utilizando-se o comprimento de onda mais adequado, ou seja, $660 \mathrm{~nm}$. Para que os resultados fossem consistentes e confiáveis, foi necessária a diluição das amostras (1:5), toda vez que a leitura preliminar de uma amostra fosse maior do que 0.600 de absorvância.

A determinação da atividade enzimática da gama glutamil transferase do soro sangüíneo mostrou ser mais um meio alternativo para a identificação indireta de bezerros imunologicamente deficientes por uma inadequada transferência passiva de imunoglobulinas. A avaliação de atividade sérica de GGT apresentou algumas qualidades fundamentais em patologia clínica: rapidez na execução, ser menos onerosa do que o teste de imunodifusão radial e produzir bons resultados para o diagnóstico de falha na transferência passiva de imunidade.

Observou-se, no soro sangüíneo de bezerros com 24 horas de vida, uma correlação positiva entre a proteína total e em relação às frações beta e gama globulinas e imunoglobulina $\mathrm{G}$, obtida através da turbidez pelo sulfato de zinco, e de IgG e IgM, obtidas pela imunodifusão radial, e a atividade sérica da GGT (Tabela 2).

\section{CONCLUSÃO}

As determinações das concentrações séricas de proteína total, das frações beta globulina e gama globulina e das imunoglobulina $\mathrm{G}$ e $\mathrm{M}$, bem como da atividade enzimática da gama glutamil tansferase no soro sangüíneo de bezerros com

Tabela 2 - Coeficiente de correlação entre os resultados determinados para a concentração de proteína total (PT), albumina (ALB), alfaglobulina (ALFA), betaglobulina (BETA), gamaglobulina (GAMA), gamaglutamil transferase (GGT), imunoglobulinas G e M/ imunodifusão radial (IgG-IR e IgM-IR) e imunoglobulina G / turbidimetria (IgG Turb.) de bezerros neonatos da raça holandesa, 24 horas após a ingestão de colostro. Significância das correlações. Araçatuba - SP, 1998.

\begin{tabular}{lcccccccc}
\hline & ALB & ALFA & BETA & GAMA & GGT & IgG - IR & IgM - IR & IgG - Turb. \\
\hline PT & 0,201 & 0,169 & $0,640 *$ & $0,942 *$ & $0,682 *$ & $0,950 *$ & $0,803 *$ & $0,925 *$ \\
ALB & 1 & $-0,024$ & $-0,099$ & $-0,049$ & $-0,004$ & $-0,026$ & 0,190 & 0,224 \\
ALFA & - & 1 & $-0,207$ & 0,032 & 0,117 & 0,244 & $0,381 *$ & 0,106 \\
BETA & - & - & 1 & $0,587 *$ & $0,499 *$ & $0,626 *$ & $0,423 *$ & $0,542 *$ \\
GAMA & - & - & - & 1 & $0,670 *$ & $0,954 *$ & $0,722 *$ & $0,885 *$ \\
GGT & - & - & - & - & 1 & $0,626 *$ & $0,575 *$ & $0,583 *$ \\
IgG - IR & - & - & - & - & - & 1 & $0,755 *$ & $0,927 *$ \\
IgM - IR & - & - & - & - & - & - & 1 & $0,814 *$ \\
IgG - Turb. & - & - & - & - & - & - & - & 1 \\
\hline
\end{tabular}

* correlação significativa ao nível de $5 \%$. 
24 horas de vida, mostraram-se eficientes para o reconhecimento daqueles que apresentaram falha na transferência de imunidade passiva. O teste de turbidez pelo sulfato de zinco por sua precisão, rapidez e baixo custo, é uma excelente alternativa para a determinação de bezerros neonatos hipogamaglobulinêmicos.

\section{AGRADECIMENTOS}

Os autores agradecem o aporte financeiro concedido pela Fundação de Amparo à Pesquisa do Estado de São Paulo FAPESP.

\section{FONTES DE AQUISIÇÃO}

1 - Bayer - Technicom modelo RA-100 system

2 - Zênite modelo Z-30 turbo

3 - Binding Site Kit para IgG, cat RN, 200.3 / 203.3

4 - Boehringer Mannheim - r - GGT MPR 1 - Kit monotest $n$. 750832 .

\section{REFERÊNCIAS BIBLIOGRÁFICAS}

BUTLER, J.E. Bovine immunoglobulins: A review. Journal of Dairy Science, v.52, n.12, p.1895-909, 1969.

BUTLER, J.E. Bovine immunoglobulins: An augmented review. Veterinary Immunology and Immunopathology, v.4, n.12, p.43-152, 1983

COLlARD, A., PIVONT, P., PORTELlE, D., et al. Isolation and purification of bovine immunoglobulins: precipitation steps. Annales de Recherches Vétérinaires, v.15, n.4, p.497-501, 1984 .

FAGLIARI, J.J., OLIVEIRA, E.C., PEGORER, M.F, et al. Relação entre o nível sérico de gamaglobulinas e as atividades de gamaglutamiltransferase, fosfatase alcalina e aspartatoaminotransferase de bezerros recém-nascidos. Arquivo Brasileiro de Medicina Veterinária e Zootecnia, v.48, n.2, p.105-112, 1996

FRIEDMAN, H.S. A standardized procedure for serum proteín eletrophoresis on cellulose acetate membrane strips. Clinica Chimica Acta, v.6, p.775-781, 1961 .

GORNALL, A.G., BARDAWILL, C.J., DAVID, M.M Determination of serum proteín by means of biuret reaction. Journal of Biological Chemistry, v. 177, p.751-766, 1949.

HEATH, S.E. Neonatal diarrhea in calves : Investigation of herd managenment practices. Compendium on Continuing Education for the Practing Veterinarian, v.14 , n.3, p.38595, 1992.

HUDGENS, K.A.R., TYLER,J.W., BESSER, T.E., $\boldsymbol{e}$ t al. Optimizing performace of a quantitative zinc sulphate turbidity test for passive transfer of immunoglobulin $G$ in calves. American Journal of Veterinary Reseach, v.57, n.12, p.1711-1713, 1996.

MANCINI, G., CARBONARA, A.O., HEREMANS, J.F. Imunochemical quantitation of antigens by single radial immunodifusion. Imunochemistry, v.2, n.3, p.235-254, 1965.

MICUNOVIC, J., ZADMIK, T., NEMEC, M., et al. Gammaglobulin status of newborn calves. Veterinarske-Novice, v.22, n.7/8, p.247-51, 1996.

NAYLOR, J.M., KRONFELD, D.S., Bech-NIELSEN, S., et al. Plasma total protein measurement for prediction of disease and mortality in calves. Journal of the American Veterinary Medical Association, v.171, n.7, p.635-638, 1977.

ODDE, K. G. Survival of neonatal calf. Veterinary Clinics of North America: Food Animal Practice, v.4, n.3, p.501-8, 1988.

PERINO, L.J., SUTHERLAND, R.L., WOOLLEN, N.E. Serum gamma-glutamyltransferase activity and protein concentration at birth and after sukling in calves with adequate and inadequate passive transfer immunoglobulin G. American Journal of Veterinary Research, v.54, n. 1, p.56-59, 1993.

PFEIFFER, N.E., McGUIRE, T.C., BENDEL, R.B. $\boldsymbol{e t}$ al. Quantitation of bovine immunoglobulins : comparison of single radial immunodiffusion, zinc sulfate turbidity, serum electrophoresis, and refractometer methods. Americam Journal of Veterinary Research, v.38, n.5, p.693-698, 1977.

REA, D.E., TYLER, J.W., HANCOCK, D.D, et al. Prediction of calf mortality by use of tests for passive transfer of colostral immunoglobulin. Journal of Americam Medical Association, v.208, n.12, p.2047-2049, 1996.

RUBIO, L., ZALDINAR, V., MAYARI, R. Cuantificación de immunoglobulinas por turbidez y su aplicación en terneros y bovinos adultos. Revista Cubana de Ciencia Veterinaria, v.22, n.2, p.113-120, 1991.

SELIM, S.A., SMITH, B.P., CULLOR, J.S., et al. Serum immuneglobulins in calves : Their effects and two easy, reliable means of measurement. Veterinary Medicine, v.90, n.4, p.387-404, 1995.

STRUFALDI, B. Prática de bioquímica clínica. São Paulo: Faculdade de Ciências Farmacêuticas da Universidade de São Paulo, 1987. 399p.

SZASZ, G. A kinetic photometric method for serum gama glutamil transpeptidase. Clinical Chemistry, v.15, n.2, p.124-135, 1969.

THOMPSON, J.C., PAULI, J.V. Colostral transfer of gamma glutamyl transpeptidase in calves. New Zealand Veterinary Journal, v.29, n.12, p.223-226, 1981.

ZAR, J.H. Biostatistical analysis. Englewood, Cliffs : PrenticeHall, 1984. 718p.

Ciência Rural, v. 31, n. 2, 2001. 